\title{
Kinematic magnetic resonance imaging study of the brain stem and cervical cord by dynamic neck motion
}

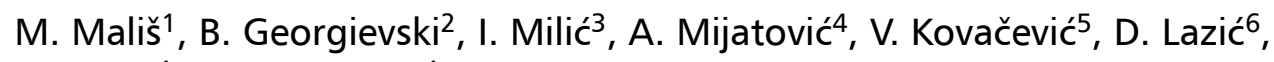 \\ S. Kapor ${ }^{1}$, S. Marinković ${ }^{1}$ \\ ${ }^{1}$ Institute of Anatomy, Faculty of Medicine, University of Belgrade, Belgrade, Serbia \\ 2Department of Magnetic Resonance Imaging, Clinic "Sveti Sava", Faculty of Medicine, University of Belgrade, \\ Belgrade, Serbia \\ ${ }^{3}$ Clinic of Neurosurgery, Faculty of Medicine, University of Belgrade, Belgrade, Serbia \\ ${ }^{4}$ Department of Neuropsychiatry, City Hospital Zvezdara, Belgrade, Serbia \\ ${ }^{5}$ Department of Cardiology, Clinical Centre of Serbia, Faculty of Medicine, University of Belgrade, Belgrade, Serbia \\ 'Psychiatric Clinic "Laza Lazarević", Faculty of Medicine, University of Belgrade, Belgrade, Serbia
}

[Received: 1 December 2015; Accepted: 19 February 2016]

Background: The aim was to examine the position of the brain stem and cervical cord following the neck flexion and extension.

Materials and methods: The serial sagittal T2-weighted magnetic resonance imaging (MRI) sections of the cervical cord and brain stem were made in 6 volunteers. The images were mainly used to measure certain distances and angles of the brain stem and cervical cord in the neutral position, and then following the head and neck flexion and extension.

Results: The measurements showed that the pons is slightly closer to the clivus following the neck flexion; the medulla oblongata is somewhat distant to the basion but closer to the odontoid process. At the same time, the spino-medullary angle diminishes in size. On the other hand, the upper cervical cord slightly approaches the posterior wall of the spinal canal, the lower cervical cord is closer to the anterior wall, while the angle between them is significantly larger in size. After the cervical cord extension, the rostral pons is somewhat distant to the clivus, whereas the caudal pons and the medulla are slightly closer to the clivus and the basion. At the same time, the spino-medullary angle diminishes in size. The cervical cord is mainly closer to the posterior wall of the spinal canal, whilst its angle is significantly smaller.

Conclusions: The obtained results regarding the brain stem and cervical cord motion can be useful in the kinetic MRI examination of certain congenital disorders, degenerative diseases, and traumatic injuries of the craniovertebral junction and the cervical spine. (Folia Morphol 2016; 75, 4: 439-447)

Key words: brain stem, craniovertebral junction, movement, radiology, spinal cord 


\section{INTRODUCTION}

The biomechanics of the cervical spine, including the craniovertebral junction (CVJ), has been examined to a certain extent in the healthy persons $[4,8,10$, $22,24,36,39]$, as well as in the patients with some congenital disorders [12, 35], degenerative spine diseases [2, 6, 21, 26-28, 31, 32, 38], rheumatoid arthritis [18], neoplastic diseases [5, 29, 33, 34], and following certain cervical spine trauma and the consecutive operations $[1,11,15,17,23,30]$.

On the other hand, dynamic movements of the cervical spinal cord were examined relatively rarely $[3,8,13,14,19,20,26,39]$. The brain stem movements were partially investigated only in a few articles $[5,7,16,27]$. In addition, some authors examined the position of the lower border of the adjacent cerebellar tonsils and the $4^{\text {th }}$ ventricle in the cervical spine flexion and extension [7, 8].

Due to scarce data in this domain, we decided to examine the movements of the spinal cord and the brain stem following flexion and extension in a group of healthy individuals.

\section{MATERIALS AND METHODS}

The magnetic resonance imaging (MRI) examination was carried out in 6 healthy volunteers aged from 29 to 41 (mean, 34.7). Written consent was provided from each of them, as well as from the Department of Radiology and the Ethics Committee of the University Clinical Centre. In each of the volunteers, 20 sections $2 \mathrm{~mm}$ in thickness were made in the sagittal plane. The subjects were examined using the 1.5 T magnetic resonance machine General Electric (GE) Sigma Hdx. The following parameters were used in the MRI procedure: T2/FRFSE, TR 4340, TE 109.6, and FOV $24 \times 24$.

Each volunteer was examined in a recumbent posture, first in a neutral position. In the next step, a maximum flexion was performed in each person, i.e. "with the chin on the chest", after placing a $25 \mathrm{~cm}$ plastic pillow below the head. Finally, a maximum extension was performed by placing a pillow under the upper scapular region of each person. In the latter case, the MRI examination took only a few minutes, in order to avoid a possible risk factor for posterior circulation stroke [37].

Certain measurements were performed in those persons (Fig. 1): a distance of the ventral surface of the pons to the clivus (a), as well as the diameter of the pons (b), at a line which starts from the fastigium and runs perpendicular to the clivus; a distance from the foramen caecum of the medulla oblongata to

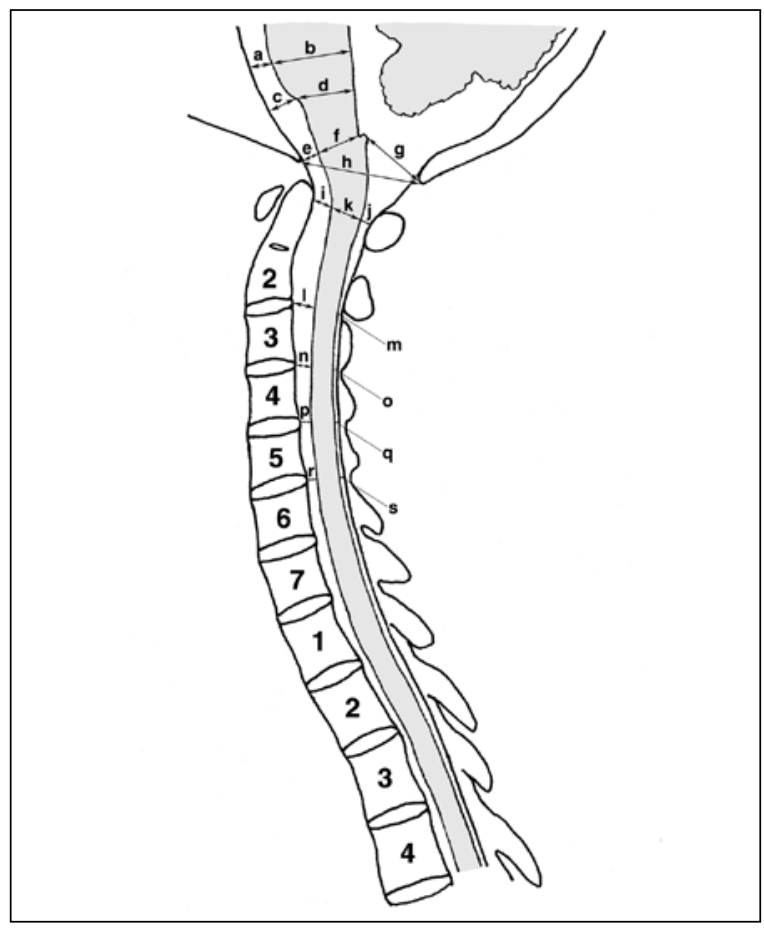

Figure 1. A schematic presentation of certain diameters and distances measured in the sagittal magnetic resonance imaging sections of the head and neck.

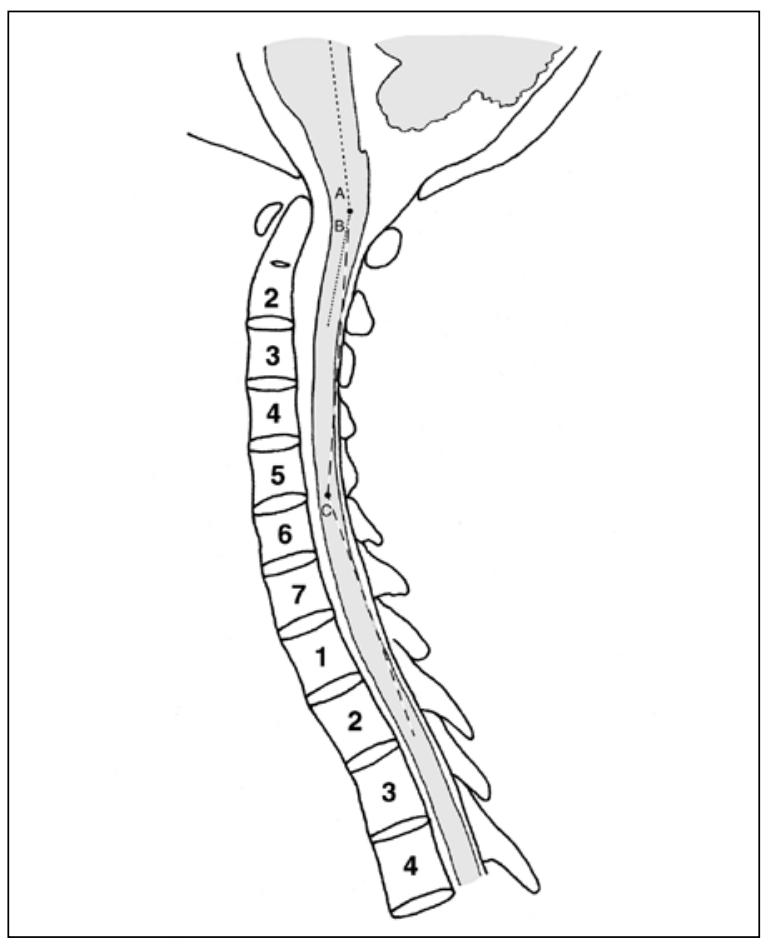

Figure 2. A schematic presentation of the angles measured in the sagittal magnetic resonance imaging sections of the head and neck.

the clivus (c) at $90^{\circ}$ to the clivus; the diameter of the rostral medulla oblongata $(d)$ from the foramen cae- 

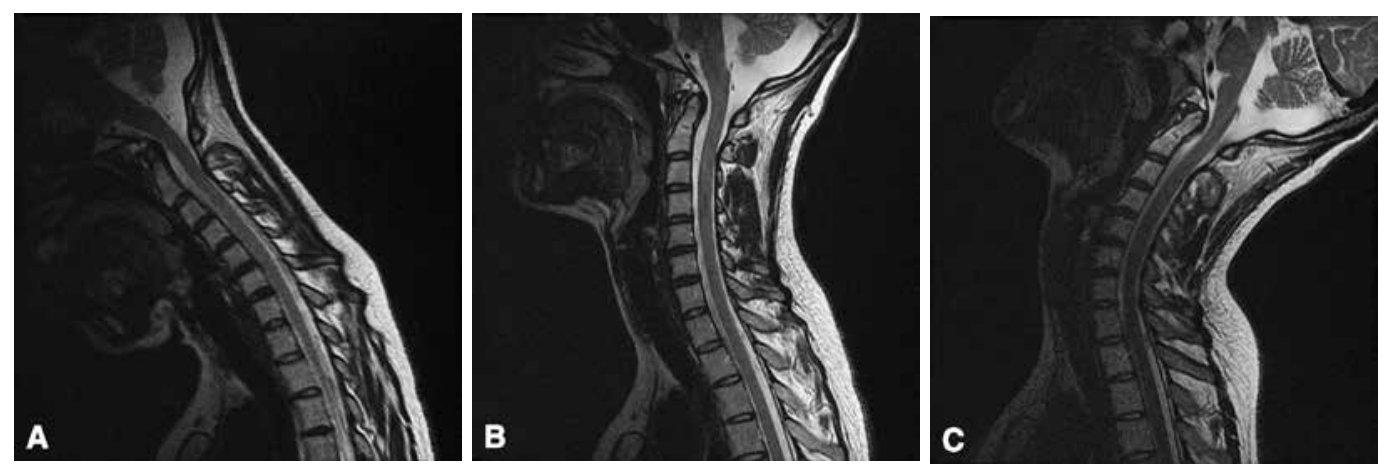

Figure 3. The sagittal magnetic resonance imaging sections of the head and neck in flexion (A), neutral position (B) and extension (C).

cum, which is perpendicular to the rhomboid fossa; a distance from the medulla to the anterior margin of the foramen magnum, i.e. to the basion (e); the diameter of the medulla at the level of the obex (f); a distance of the area postrema to the posterior margin of the foramen magnum, i.e. to the opisthion (g); the sagittal diameter of the foramen magnum (h); a distance of the spinal cord to the level just below the tip of the odontoid process (i), which is situated on a line connecting the upper margin of the anterior arch of the atlas and the middle of the anterior surface of the posterior arch of the atlas; a distance of the spinal cord to the middle of the anterior surface of the posterior arch of the atlas (j); the diameter of the spinal cord at the same level ( $k$ ); a similar distances as in ' $i$ ' and ' $j$ ' of the spinal cord to the cervical spine at the level of the intervertebral discs $\mathrm{C} 2 / \mathrm{C} 3, \mathrm{C} 3 / \mathrm{C} 4$, and $\mathrm{C} 5 / \mathrm{C} 6$, that is, the $\mathrm{l}, \mathrm{m}, \mathrm{n}, \mathrm{o}, \mathrm{p}, \mathrm{q}, \mathrm{r}$ and $\mathrm{s}$ parameters (Fig. 1).

In addition, 3 angles were measured (Fig. 2). Firstly, between a point in the middle of the transition region of the spinal cord and medulla oblongata, at the level just below the tip of the odontoid process, whose upper limb is parallel to the rhomboid fossa, whereas the lower limb passes along the axis of the spinal cord to the level of the C2/C3 discus (angle A). Secondly, between the upper limb of the previous angle and the lower limb which runs through a point in the middle of the spinal cord at the level of the $\mathrm{C} 5 / \mathrm{C} 6$ disc (angle B); and between the upper limb of the previous angle and a lower limb which passes through the middle of the spinal cord at the level of the T2/T3 disc (angle C).

The statistics comprised minimum and maximum values, as well as counting the mean value, standard deviation (SD) and confidence interval. The ANOVA test was applied as well.

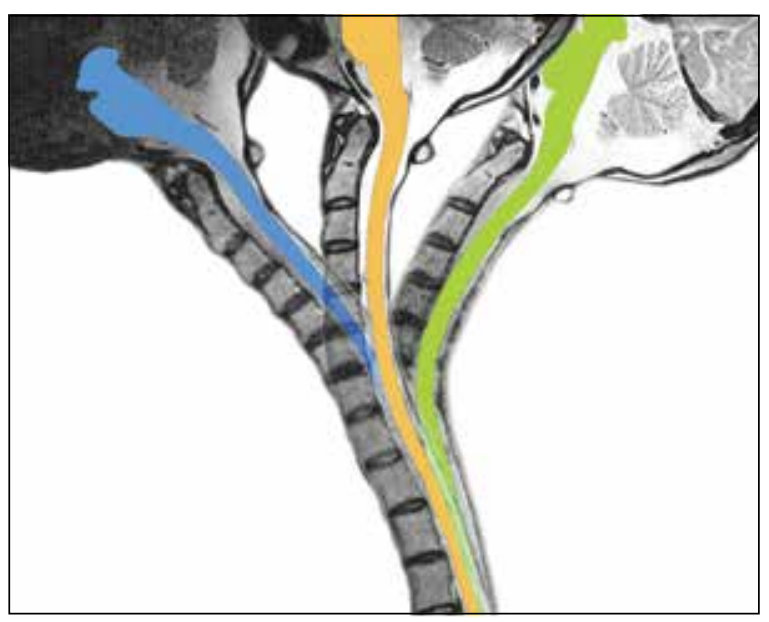

Figure 4. The sagittal magnetic resonance imaging pictures in three positions, i.e. flexion (blue), neutral (orange) and extension (green), overlapped at the level of the T5 vertebra.

\section{RESULTS}

As already mentioned, the serial sagittal T2-weighted MRI sections were performed in the neutral posture, flexion and extension of the cervical spine of the volunteers (Fig. 3). The MRI pictures of each person were overlapped to show the angle differences between the three positions of his or her head and neck (Fig. 4).

\section{Measurement of distances and diameters}

We measured the parameters from ' $a$ ' to ' $s$ ', which were defined in the 'Materials and methods' section. They were examined in the neutral cervical spine position (Table 1), and in flexion (Table 2) and extension (Table 3), respectively.

The parameter 'a' measurement, i.e. the distance between the pons and the clivus (Fig. 1), diminished in size after flexion in a range of $0.4-2.0 \mathrm{~mm}$ (mean, $0.92 \mathrm{~mm}$ ) as compared with the neutral position 
Table 1. Measurements $[\mathrm{mm}]$ in neutral cervical spine position

\begin{tabular}{lccc}
\hline $\begin{array}{l}\text { Para- } \\
\text { meters }\end{array}$ & $\begin{array}{c}\text { Max-min (mean) } \pm \\
\pm \text { standard deviation }\end{array}$ & \multicolumn{2}{c}{ 95\% confidence interval } \\
\cline { 3 - 4 } & & $\begin{array}{c}\text { Lower } \\
\text { bound }\end{array}$ & $\begin{array}{c}\text { Upper } \\
\text { bound }\end{array}$ \\
\hline $\mathrm{a}$ & $3.8-8.1(6.58) \pm 1.54$ & 4.97 & 8.19 \\
$\mathrm{c}$ & $8.6-11.9(10.23) \pm 1.29$ & 8.88 & 11.59 \\
$\mathrm{e}$ & $5.4-8.1(6.52) \pm 1.22$ & 5.24 & 7.79 \\
$\mathrm{~g}$ & $16.7-23.2(19.53) \pm 2.40$ & 17.01 & 22.06 \\
$\mathrm{i}$ & $2.4-3.6(3.03) \pm 0.49$ & 2.52 & 3.55 \\
$\mathrm{j}$ & $3.4-5.6(4.48) \pm 0.85$ & 3.59 & 5.38 \\
$\mathrm{I}$ & $1.9-5.0(3.7) \pm 1.09$ & 2.55 & 4.85 \\
$\mathrm{~m}$ & $0.0-3.1(1.72) \pm 1.13$ & 0.53 & 2.91 \\
$\mathrm{n}$ & $1.5-2.8(2.45) \pm 0.48$ & 1.95 & 2.95 \\
$\mathrm{o}$ & $0.0-4.6(2.25) \pm 1.62$ & 0.55 & 3.95 \\
$\mathrm{p}$ & $1.8-3.1(2.38) \pm 0.43$ & 1.94 & 2.83 \\
$\mathrm{q}$ & $1.4-5.8(2.83) \pm 1.71$ & 1.04 & 4.63 \\
$\mathrm{r}$ & $0.9-3.5(2.53) \pm 0.88$ & 1.61 & 3.45 \\
$\mathrm{~s}$ & $0.8-4.8(1.98) \pm 1.46$ & 0.45 & 3.51 \\
\hline
\end{tabular}

Table 2. Measurements [mm] following cervical spine flexion

\begin{tabular}{lccc}
\hline $\begin{array}{l}\text { Para- } \\
\text { meters }\end{array}$ & $\begin{array}{c}\text { Min-max (mean) } \pm \\
\text { I standard deviation }\end{array}$ & \multicolumn{2}{c}{ 95\% confidence interval } \\
\cline { 3 - 4 } & & $\begin{array}{c}\text { Lower } \\
\text { bound }\end{array}$ & $\begin{array}{c}\text { Upper } \\
\text { bound }\end{array}$ \\
\hline $\mathrm{a}$ & $3.10-7.10(5.92) \pm 1.53$ & 4.31 & 7.52 \\
$\mathrm{c}$ & $9.80-12.60(11.40) \pm 1.09$ & 10.25 & 12.55 \\
$\mathrm{e}$ & $1.50-8.90(6.17) \pm 2.62$ & 3.42 & 8.92 \\
$\mathrm{~g}$ & $16.00-21.10(18.22) \pm 2.36$ & 15.74 & 20.70 \\
$\mathrm{i}$ & $1.70-3.00(2.28) \pm 0.58$ & 1.67 & 2.89 \\
$\mathrm{j}$ & $3.10-6.50(4.63) \pm 1.49$ & 3.06 & 6.20 \\
$\mathrm{I}$ & $2.80-5.50(4.17) \pm 0.97$ & 3.15 & 5.18 \\
$\mathrm{~m}$ & $0.00-2.30(1.27) \pm 0.83$ & 0.40 & 2.14 \\
$\mathrm{n}$ & $1.30-2.90(2.22) \pm 0.71$ & 1.47 & 2.97 \\
$\mathrm{O}$ & $0.60-3.30(2.38) \pm 0.96$ & 1.38 & 3.39 \\
$\mathrm{p}$ & $0.90-2.20(1.43) \pm 0.43$ & 0.98 & 1.89 \\
$\mathrm{q}$ & $1.30-5.90(3.55) \pm 1.57$ & 1.90 & 5.20 \\
$\mathrm{r}$ & $1.40-2.70(2.17) \pm 0.55$ & 1.59 & 2.74 \\
$\mathrm{~s}$ & $1.20-5.00(2.63) \pm 1.49$ & 1.07 & 4.20 \\
\hline
\end{tabular}

(Table 2). In 1 person only the distance was $0.6 \mathrm{~mm}$ longer. During extension, however, the distance was $0.6-4.3 \mathrm{~mm}$ (mean, $1.55 \mathrm{~mm}$ ) longer in length in most volunteers. In the remaining 2 persons the distance was $0.1 \mathrm{~mm}$ and $1.6 \mathrm{~mm}$ shorter. However, there was no significant difference among the
Table 3. Measurements [mm] following cervical spine extension

\begin{tabular}{lccc}
\hline Para- & Min-max (mean) \pm \\
meters & \pm standard deviation & \multicolumn{2}{c}{ 95\% confidence interval } \\
\cline { 3 - 4 } & & $\begin{array}{c}\text { Lower } \\
\text { bound }\end{array}$ & $\begin{array}{c}\text { Upper } \\
\text { bound }\end{array}$ \\
\hline $\mathrm{a}$ & $4.50-9.10(7.43) \pm 1.59$ & 5.77 & 9.10 \\
$\mathrm{C}$ & $8.10-11.50(9.87) \pm 1.33$ & 8.47 & 11.26 \\
$\mathrm{e}$ & $4.50-8.00(6.12) \pm 1.48$ & 4.57 & 7.67 \\
$\mathrm{~g}$ & $16.00-21.70(18.17) \pm 2.15$ & 15.91 & 20.43 \\
$\mathrm{i}$ & $2.80-4.10(3.35) \pm 0.50$ & 2.83 & 3.87 \\
$\mathrm{j}$ & $3.10-5.40(4.37) \pm 0.84$ & 3.49 & 5.24 \\
$\mathrm{I}$ & $1.60-5.10(3.87) \pm 1.28$ & 2.52 & 5.21 \\
$\mathrm{~m}$ & $1.40-3.40(2.42) \pm 0.78$ & 1.60 & 3.23 \\
$\mathrm{n}$ & $1.40-4.10(2.82) \pm 0.87$ & 1.91 & 3.73 \\
$\mathrm{O}$ & $1.50-4.30(2.75) \pm 1.08$ & 1.61 & 3.89 \\
$\mathrm{p}$ & $1.70-3.50(2.45) \pm 0.62$ & 1.80 & 3.10 \\
$\mathrm{q}$ & $1.80-3.90(2.48) \pm 0.83$ & 1.61 & 3.35 \\
$\mathrm{r}$ & $1.60-2.30(1.98) \pm 0.28$ & 1.69 & 2.28 \\
$\mathrm{~s}$ & $0.60-3.50(1.62) \pm 0.99$ & 0.58 & 2.66 \\
\hline
\end{tabular}

neutral position and flexion $(p<0.741)$, the neutral position and extension $(p<0.619)$, and flexion and extension $(p<0.240)$, neither in a single individual nor following comparison in the whole group of the volunteers.

As regards the ' $b$ ' parameter, that is, the diameter of the pons, it was measured only in the neutral position. This was the same situation with the ' $d$ ', ' $f$ ' and ' $k$ ' parameters (Fig. 1). Similar parameters have already been measured by other authors $[18,21]$. At any rate, the ' $b$ ' parameter measured $20.9-24.8 \mathrm{~mm}$ (mean, $22.8 \mathrm{~mm}$ ) in length, the ' $d$ ' was $12.0-16.1 \mathrm{~mm}$ (mean, $14.0 \mathrm{~mm}$ ), the ' $\mathrm{f}$ ' was $10.3-13.7 \mathrm{~mm}$ (mean, $11.9 \mathrm{~mm}$ ), and the ' $\mathrm{k}$ ' measured 7.5-10.1 mm (mean, $7.9 \mathrm{~mm}$ ) in a neutral position. The ' $h$ ' parameter, i.e. the sagittal diameter of the foramen magnum, does not depend on the head and neck position. It ranged from $30.2 \mathrm{~mm}$ to $36.1 \mathrm{~mm}$ in length and averaged $33.5 \mathrm{~mm}$.

The ' $c$ ' parameter showed an increase of 0.6$-2.2 \mathrm{~mm}$ (mean, $1.17 \mathrm{~mm}$ ) after flexion when compared with the neutral position. It was diminished 0.2 $-1.1 \mathrm{~mm}$ (mean, $0.65 \mathrm{~mm}$ ) in length after extension in all the persons except one. However, none of these results were statistically significant.

The ' $e$ ' parameter presented an increase in length between $0.4 \mathrm{~mm}$ and $0.8 \mathrm{~mm}$ (mean, $0.52 \mathrm{~mm}$ ) in 
flexion in most of the volunteers. There were, however, the lower values, i.e. from $0.1 \mathrm{~mm}$ to $1.3 \mathrm{~mm}$ (mean, $0.8 \mathrm{~mm}$ ), following the spine extension. No statistically significant difference was observed.

The ' $g$ ' parameter in flexion showed a decrease in length from $0.5 \mathrm{~mm}$ to $3.6 \mathrm{~mm}$ (mean, $1.47 \mathrm{~mm}$ ) in 4 persons, but an increase of $0.2 \mathrm{~mm}$ and $0.8 \mathrm{~mm}$ in 2 individuals. Similarly, a decrease was noticed in most persons, ranging from $0.7 \mathrm{~mm}$ to $3.8 \mathrm{~mm}$ (mean, $1.8 \mathrm{~mm}$ ), following extension, but without a statistical significance.

The ' $i$ ' parameter diminished 0.1-1.7 mm (mean, $0.96 \mathrm{~mm}$ ) in length after flexion, and it increased $0.1-1.9 \mathrm{~mm}$ (mean, $1.08 \mathrm{~mm}$ ) in length following extension. There is a high statistical difference $(p<$ $<0.008$ ) between the values in flexion and extension.

The ' $\mathrm{j}$ ' parameter diminished in a half of the persons $(0.3-0.8 \mathrm{~mm}$; mean, $0.4 \mathrm{~mm})$, but increased in the rest $(0.1-0.7 \mathrm{~mm}$; mean, $0.3 \mathrm{~mm})$ in flexion. Similarly, it was $0.4-0.5 \mathrm{~mm}$ (mean, $0.44 \mathrm{~mm}$ ) larger in a half of the subjects following extension, but $0.3-0.8 \mathrm{~mm}$ (mean, $0.5 \mathrm{~mm}$ ) smaller or unchanged in the remaining volunteers.

The 'I' parameter was $0.2-1.9 \mathrm{~mm}$ (mean, $0.78 \mathrm{~mm}$ ) longer in flexion. It diminished in size in 2 persons $(0.1 \mathrm{~mm}$ and $0.3 \mathrm{~mm}$, respectively) after extension, but it increased in another 2 persons $(0.4 \mathrm{~mm}$ and $0.6 \mathrm{~mm})$, and was unchanged in the remaining individuals.

The ' $m$ ' parameter was unchanged in 2 persons after flexion, and it was smaller in the remaining individuals $(0.5-1.4 \mathrm{~mm}$; mean, $0.67 \mathrm{~mm})$. It was larger in all the volunteers $(0.1-2.1 \mathrm{~mm}$; mean, $0.87 \mathrm{~mm}$ ) in extension. There was a statistically significant difference between the values during flexion and extension $(p<0.045)$.

The ' $n$ ' parameter was longer in 4 persons $(0.1-$ $-0.7 \mathrm{~mm}$; mean, $0.3 \mathrm{~mm}$ ) after flexion, and it was shorter in the remaining 2 persons $(0.7 \mathrm{~mm}$ and $1.2 \mathrm{~mm}$, respectively). It was longer in all the individuals (0.2$-1.3 \mathrm{~mm}$; mean, $0.46 \mathrm{~mm}$ ) after extension.

The ' 0 ' parameter increased in 4 persons (0.3$-1.4 \mathrm{~mm}$; mean, $0.92 \mathrm{~mm}$ ) after flexion, and it decreased in 2 subjects $(0.6 \mathrm{~mm}$ and $2.6 \mathrm{~mm}$ ). This parameter was longer in 5 individuals $(0.1-1.5 \mathrm{~mm}$; mean, $0.66 \mathrm{~mm})$ in extension, and shorter in only one $(0.3 \mathrm{~mm})$.

The ' $p$ ' parameter was smaller in all the volunteers (0.1-0.4 mm; mean, $0.22 \mathrm{~mm}$ ) after flexion, which was a statistically significant difference $(p<0.013)$. It was larger in 5 persons $(0.1-0.4 \mathrm{~mm}$; mean, $0.22 \mathrm{~mm}$ ) following extension, and smaller in only one $(0.7 \mathrm{~mm})$. The flexion/extension difference was highly significant $(p<0.008)$.

The ' $q$ ' parameter was longer virtually in all individuals $(0.1-2.6 \mathrm{~mm}$; mean, $0.88 \mathrm{~mm}$ ) after flexion. It was shorter in 3 persons $(1.2-1.9 \mathrm{~mm}$; mean, $1.27 \mathrm{~mm}$ ) after extension, and longer in the remaining subjects (0.4-1.4 mm; mean, $0.90 \mathrm{~mm}$ ).

The ' $r$ ' parameter was smaller in practically all the subjects $(0.2-1.9 \mathrm{~mm}$; mean, $0.54 \mathrm{~mm})$ in flexion, and it was larger in all the individuals $(0.1-2.1 \mathrm{~mm}$; mean, $0.87 \mathrm{~mm}$ ) in extension.

The ' $s$ ' parameter increased in all the volunteers $(0.2-1.3 \mathrm{~mm}$; mean, $0.48 \mathrm{~mm})$ after flexion. It diminished in size virtually in all the individuals $(0.2-1.3 \mathrm{~mm}$; mean, $0.52 \mathrm{~mm}$ ) in extension.

\section{The angles measurement}

As regards the angles (Fig. 2; Table 4), the first of them (angle $A$ ) was, in fact, the spino-medullary angle between the most rostral part of the cervical cord and the brain stem. The second one (angle B) represented the angle between the brain stem and the upper cervical cord. The third one (angle C) was actually the angle between the upper and lower cervical cord, including the most rostral portion of the thoracic cord. The obtained values were compared in each volunteer in the three positions (neutral, flexion, and extension), and then among all the examined persons in these positions.

Angle $A$ was smaller after flexion in 4 volunteers $\left(1-8^{\circ} ;\right.$ mean, $\left.3.7^{\circ}\right)$ and larger in 2 persons, but only between $1^{\circ}$ and $3^{\circ}$, respectively, as compared with the neutral spine position. It was larger in 4 individuals after extension (2-6 $6^{\circ}$, and smaller in 2 cases ( $5^{\circ}$ each) (Table 4, Fig. 4). There was no significant statistical difference.

Angle B was smaller after flexion in 4 persons (2-19 ${ }^{\circ}$; mean, $\left.10.2^{\circ}\right)$, and larger in the remaining 2 individuals ( $3^{\circ}$ and $4^{\circ}$, respectively). Following extension, the angle increased in 4 volunteers ( $5-7^{\circ}$; mean, $\left.6.2^{\circ}\right)$ and decreased in $2\left(4^{\circ}\right.$ and $7^{\circ}$, respectively). A significant difference was not found.

Angle $C$ was larger following flexion in all the volunteers $\left(11-48^{\circ}\right.$; mean, $\left.23.3^{\circ}\right)$. Conversely, it was smaller following extension in all persons (19-310; mean, $26.0^{\circ}$ ). There was a highly significant difference of the values between the neutral spinal position and flexion, the neutral position and extension, and flexion and extension ( $p<0.0001$ each). 
Table 4. The values of the angles (degree) in three cervical spine positions

\begin{tabular}{llcc}
\hline Position & Angles & Min-max (mean) \pm standard deviation & 95\% confidence interval: lower/upper bound \\
\hline Neutral & Angle A & $159-176(167.17) \pm 6.05$ & $160.82 / 173.51$ \\
& Angle B & $168-191(179.17) \pm 8.93$ & $169.79 / 188.54$ \\
& Angle C & $137-159(153.00) \pm 8.32$ & $169.79 / 161.73$ \\
\hline Flexion & Angle A & $159-175(165.33) \pm 7.23$ & $157.75 / 172.92$ \\
& Angle B & $156-190(173.17) \pm 10.98$ & $161.64 / 184.69$ \\
& Angle C & $170-185(176.33) \pm 6.35$ & $169.67 / 182.99$ \\
\hline Extension & Angle A & $162-177(167.67) \pm 5.47$ & $161.93 / 173.40$ \\
& Angle B & $174-188(181.50) \pm 5.47$ & $176.12 / 186.88$ \\
& Angle C & $111-138(127.00) \pm 9.32$ & $117.22 / 136.78$ \\
\hline
\end{tabular}

\section{DISCUSSION}

Our results will be discussed in the light of the variations of the parameters following the neutral position, flexion and extension, respectively, and then in relation to the angles in the three positions.

\section{The cervical spine flexion}

The parameter ' $a$ ' diminishes in length, i.e. the pons is approaching the clivus. At the same time, the ' $c$ ' and ' $e$ ' parameter increase in length, so that the medulla oblongata is getting somewhat further from the basion. On the other hand, since the ' $g$ ' parameter is shorter, the medulla approaches the opisthion.

Taking into account that the ' $i$ ' parameter diminishes in length, the odontoid process approximates the medulla oblongata. At the same time, the ' $j$ ' parameter increases in length in some volunteers, but decreases in the remaining persons. This could mean that there are some changes in the diameter of the cervical canal at this level in flexion. Endo et al. [8] concluded that the canal increases in length after flexion, i.e. its diameter is about $1 \mathrm{~mm}$ longer $[6,13]$.

The ' $l$ ' and ' $n$ ' parameters increase in length, which means that the cervical cord is getting slightly further from the anterior wall of the spinal canal at the level of the $\mathrm{C2}-\mathrm{C} 3$ and the $\mathrm{C} 3-\mathrm{C} 4$ intervertebral disks. At the same time, the ' $m$ ' and ' $o$ ' parameters are somewhat variable. Finally, the smaller ' $p$ ' and ' $r$ ' parameters indicate that the cervical cord approaches the $\mathrm{C} 4 / \mathrm{C} 5$ and $\mathrm{C} 5 / \mathrm{C} 6$ intervertebral disks. On the opposite site, the ' $q$ ' and ' $s$ ' parameters are larger in size.

\section{The cervical spine extension}

The 'a' parameter shows an increase in length in the majority of the volunteers. On the other hand, the ' $c$ ' parameter decreases in most of the individuals, as the ' $e$ ' parameter does. This means that the rostral pons moves slightly away from the clivus, whereas the caudal pons and the medulla are approaching the clivus and the basion.

The ' $i$ ' parameter increases in length in all the subjects, whereas the ' $j$ ' parameter decreases in size in most of the individuals. In other words, the medulla is here slightly more distant to the odontoid process.

The 'I' parameter shows some variability: it can be increased, decreased or unchanged. The ' $\mathrm{m}$ ' parameter is larger in all the persons. The ' $n$ ', ' $p$ ' and ' $r$ ' parameters are also increased in all the cases, indicating that the cervical cord here is slightly distant to the anterior wall of the spinal canal. The ' $o$ ' parameter is increased, whereas the ' $q$ ' parameter is either increased or decreased, respectively. It seems that the cervical canal here changes its diameter. The other authors registered a slight narrowing of the canal in extension $[6,8,13]$. Finally, the parameter ' $s$ ' is decreased in most individuals, which means that the cervical cord at this level is slightly closer to the posterior wall of the spinal canal.

\section{The angles analysis}

Angle $A$ is, actually, the spino-medullary angle (Fig. 2). It was somewhat smaller in most individuals after the spine flexion. It was larger, however, in the majority of the persons following the spine extension.

A similar situation occurred with angle $B$; that is, it was most often smaller after flexion, but larger following extension in the majority of the volunteers. 
The angle $C$ was significantly larger after flexion $(p<0.0001)$ in all the volunteers. On theother hand, it was significantly smaller following extension $(p<0.0001)$.

\section{General discussion}

The parameters' measurement after the cervical spine flexion showed a closer position of the pons to the clivus, but a slightly larger distance of the medulla to the clivus and the basion in the majority of the persons. It is obvious that certain individual variations exist in our group of the volunteers. Similarly, Doursounian et al. [7] noticed that the free space in front of the pons is narrowed in $61 \%$ of the examined persons, and in front of the medulla in $77.8 \%$, but unchanged or larger in the remaining individuals.

As regards the adjacent structures, an ascending or descending movement of the cerebellar tonsil (1 $\mathrm{mm}$ on average) was observed by Endo et al. [8]. On the other hand, a slight downward shift of the $4^{\text {th }}$ ventricle was noticed by Doursounian et al. [7].

The medulla just below the level of the foramen magnum is slightly closer to the odontoid process after flexion in our volunteers. It is most likely due to an increase of the atlas-dens interval during flexion [27]. This interval is much longer following a transverse ligament rupture [25].

The upper cervical cord is usually slightly distant from the anterior wall of the spinal canal, whereas the lower cord is usually closer to the same wall in flexion. The other authors noticed that the cervical cord is $11.7 \mathrm{~mm}$ on average longer from extension to flexion [8]. During elongation, the posterior surface of the cord increases by $10 \%$, whereas the anterior surface increases by $6 \%$ [39]. According to the latter authors, the upper cord moves caudalwards, and the lower cord moves rostralwards during flexion. The elongation is accompanied by a smaller cross-sectional area of the cord in flexion [19, 22]. The elongation is most likely due to the cord's sliding along the cervical canal, together with the spinal nerve roots.

It is understandable that the brain stem follows the mentioned axial movement of the cervical cord. According to Ji and Margulies [16], during the head and neck flexion, the pons moves about $2 \mathrm{~mm}$ rostrally or caudally, respectively, depending on the spinal cord tension and gravity.

Following the spine extension, our parameters showed that the rostral pons is somewhat distant from the clivus, whereas the caudal pons and the medulla are closer to the clivus and the basion. In addition, the medulla is slightly away from the odontoid process.

As for the cervical cord, it is most often slightly distant from the anterior wall of the spinal canal. Miura et al. [26] noticed that an average cord distance in the maximum extension position was smaller at the $\mathrm{C} 4 / \mathrm{C} 5$ and $\mathrm{C} 5 / \mathrm{C} 6$ level. The cervical cord is shorter following extension and it has a larger cross-sectional area $[6,14,19,22]$. There is a reduction of up to $1.5 \mathrm{~mm}$ of the cervical canal diameter, and its shortening after extension $[8,13]$.

The analysis of the angles during the spine movements shows, firstly, that the spino-medullary angles $A$ and $B$ were usually smaller in the spine flexion and larger after extension, but most often a few degrees only. This was also confirmed by other authors [28]. According to Doursounian et al. [7], the spino-medullary angle varies from $1^{\circ}$ to $32^{\circ}$ (mean, $14^{\circ}$ ) in flexion. We found a smaller angle $A\left(1-8^{\circ} ;\right.$ mean, $\left.3.7^{\circ}\right)$, and a larger angle $B\left(2^{\circ}\right.$ to $19^{\circ} ;$ mean, $\left.10.2^{\circ}\right)$ from neutral to flexion in the majority of the volunteers.

As regards the angle $C$, its values are significantly higher after the spine flexion, but much lower in extension $(p<0.0001)$. This was also confirmed by the findings of certain authors [27]. In other words, the movements were much more expressed in the region of the cervical cord than between it and the brain stem. To prove this visually, we overlapped the images of the three positions of the cervical spine and the skull at the level of the brain stem of each volunteer (Fig. 5). The other authors revealed that most of the total angular mobility of the cervical spine is at the C4/C5 and C5/C6 levels [28].

Most of the parameters measured in the sagittal MRI scans of our subjects are, de facto, related to the diameters of the anterior and posterior spinal subarachnoid space filled with the cerebrospinal fluid (CSF). The CVJ is a transition zone between the mentioned spinal space and the similar compartments of the posterior cranial fossa, especially the premedullary and the cerebellomedullary cisterns [9].

The cerebrospinal hydrodynamics are, in fact, the relationships between the volume, pressure, and flow of blood and CSF. Dynamics, which are mainly driven by arterial pulsations, are modified by respiration, but also by upright posture, recumbent position, and cervical spine movements. In the upright posture, for instance, the arterial pulsations during a systole pump a larger volume of blood into the spinal and cerebral arteries. This causes some rise in the intracranial arterial pressure, which is 


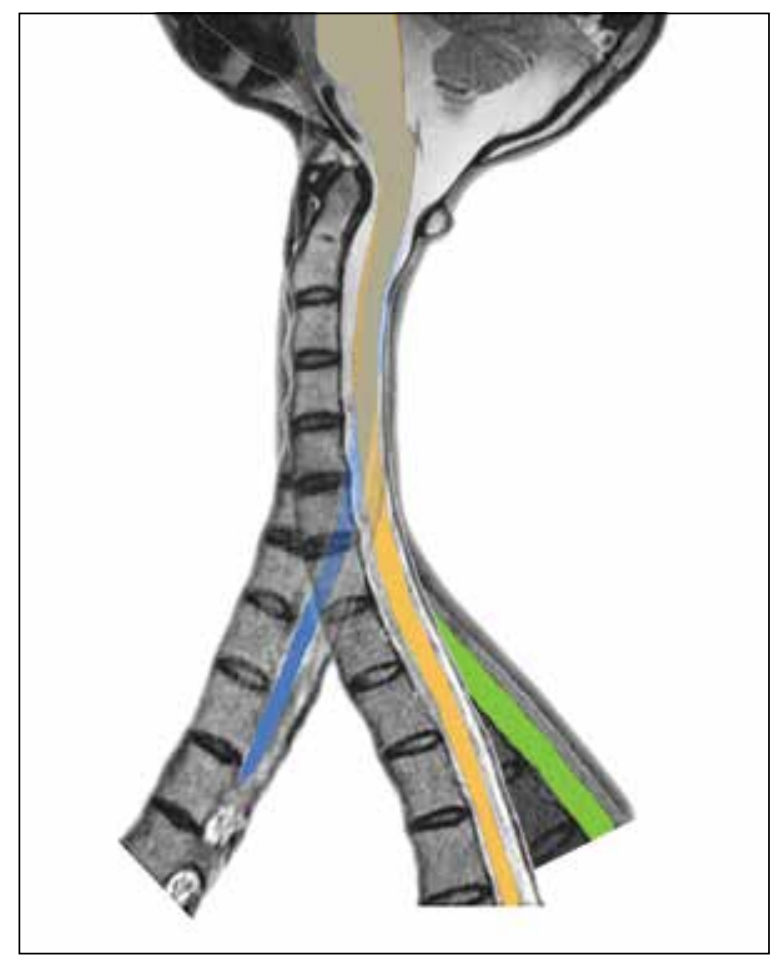

Figure 5. The sagittal magnetic resonance imaging pictures from Figure 4 overlapped in the region of the skull and brain stem.

compensated by an immediate increase in the CSF and venous blood drainage, not only via the internal jugular vein but also through the corresponding emissary veins, which link certain dural sinuses to the vertebral venous plexuses [9].

In any case, there is enough CSF reserve for a normal spinal cord displacement in flexion and extension. However, complex patterns of the pressure waves and the pressure gradient of the CSF and blood are expressed in the patients with Chiari malformations, syringomyelia, migraines, and the CVJ malformations and diseases [9]. In most of these subjects, dissociation occurs between the intracranial and the spinal pressure pulses of the CSF.

Our data obtained by measuring the mentioned parameters and angles may help in assessing the cervical cord and brain stem positions and movements in certain disorders, diseases and traumatic injures of the cervical spine $[5,11,12,17,18,21,23,29-35,38]$. This is especially true for the corresponding spine and CVJ degenerative diseases $[2,6,21,26,38]$. A dynamic MRI examination of the cervical spine and CVJ is very important clinically, because the static MRI can show only morphological changes in this region, but not their behaviour during movements $[6,21]$.
As already mentioned, the cervical spine and cord elongate during flexion, the spinal canal increases in diameter, the spinal cord becomes thinner, and the anterior subarachnoid space is slightly larger in the upper part but narrower in the lower part of the canal. In patients with spondylosis, there is a marked compression of the nerve roots or the spinal cord occasionally by the osteophytes following flexion [6]. Similarly, detection of disc herniation and, eventually, spinal cord compression rises by $5.78-19.46 \%$ in the same position [21].

On the other hand, the cervical spine and cord are shortened during extension, whilst the spinal cord is wider and closer to the posterior wall of the spinal canal. Due to that, there is an increase of the spinal canal stenosis and a cord compression by the posterior ligaments thickening and by retrolisthesis in extension [6, 31].

It is obvious that a dynamic MRI is especially useful in spondylotic myelopathy, disc herniation, and ligamenta flava diseases, as well as in the follow-up of the symptomatic patients, and in the preoperative evaluation of the cervical cord and the spinal canal conditions $[5,6,8,23,26-28,31,38]$.

\section{CONCLUSIONS}

Our study showed that the brain stem slightly changed its position during the cervical spine flexion and extension, respectively. However, the greatest amplitudes of the movements were expressed at the level of the lower cervical cord in both flexion and extension. The obtained findings could be important when assessing the dynamic factor in cervical spondylotic myelopathy, cervical spine trauma and certain congenital disorders in this region.

\section{Acknowledgements}

This work was supported by grant No. 175061 from the Ministry of Science, Serbia. We are very grateful to Ms. Elza Holt for reviewing the English text of our manuscript

\section{REFERENCES}

1. Anderson PA, Sasso RC, Hipp J, Norvell DC, Raich A, Hashimoto R (2012) Kinematics of the cervical adjacent segments after disc arthroplasty compared with anterior discectomy and fusion: a systematic review and metaanalysis. Spine (Phila Pa 1976), 37(suppl): S85-S95.

2. Benglis $D$, Levi $A D(2010)$ Neurologic findings of craniovertebral junction disease. Neurosurgery, 66 (suppl): A13-A21.

3. Bilston LE, Thibault LE (1996) The mechanical properties of the human cervical spinal cord in vitro. Ann Biomed Eng, 24: 67-74. 
4. Board D, Stemper BD, Yoganandan N, Pintar FA, Shender B, Paskoff $\mathrm{G}$ (2006) Biomechanics of the aging spine. Biomed Sci Instrum, 42: 1-6.

5. D'Andrea K, Dreyer J, Fahim DK (2015) Utility of preoperative magnetic resonance imaging coregistered with intraoperative computed tomographic scan for the resection of complex tumors of the spine. World Neurosurg, 84: 1804-1815.

6. Dalbayrak S, Yaman O, Firidin MN, Yilmaz T, Yilmaz M (2015) The contribution of cervical dynamic magnetic resonance imaging to the surgical treatment of cervical spondylotic myelopathy. Turk Neurosurg, 25: 36-42.

7. Doursounian L, Alfonso JM, Iba-Zizen MT, Roger B, Cabanis EA, Meininger V, Pineau H (1989) Dynamics of the junction between the medulla and the cervical spinal cord: an in vivo study in the sagittal plane by magnetic resonance imaging. Surg Radiol Anat, 11: 313-322.

8. Endo K, Suzuki H, Nishimura H, Tanaka H, Shishido T, Yamamoto K (2014) Kinematic analysis of the cervical cord and cervical canal by dynamic neck motion. Asian Spine J, 8: 747-752.

9. Flanagan MF (2015) The role of the craniocervical junction in craniospinal hydrodynamics and neurodegenerative conditions. Neurol Res Int, ;2015:794829. doi:10.1155/2015/794829.

10. Gerigk L, Bostel T, Hegewald A, Thomé C, Scharf J, Groden C, Neumaier-Probst E (2012) Dynamic magnetic resonance imaging of the cervical spine with high-resolution 3-dimensional T2-imaging. Clin Neuroradiol, 22: 93-99.

11. Ghasemi A, Haddadi K, Shad AA (2015) Comparison of diagnostic accuracy of MRI with and without contrast in diagnosis of traumatic spinal cord injuries. Medicine (Baltimore), 94: e1942.

12. Hankinson TC, Anderson RCE (2010) Craniovertebral junction abnormalities in Down syndrome. Neurosurgery, 66 (suppl.): A32-A38.

13. Harrison DE, Cailliet R, Harrison DD, Troyanovich SJ, Harrison SO (1999a) A review of biomechanics of the central nervous system - part I: spinal canal deformations resulting from changes in posture. J Manipulative Physiol Ther, 22: 227-234.

14. Harrison DE, Cailliet R, Harrison DD, Troyanovich SJ, Harrison SO (1999b) A review of biomechanics of the central nervous system - part II: spinal cord strains from postural loads. J Manipulative Physiol Ther, 22: 322-332.

15. Hsu W, Wolinsky J-P, Gokaslan ZL, Sciubba DM (2010) Transoral approaches to the cervical spine. Neurosurgery, 66 (suppl.): A119-A125.

16. Ji S, Margulies SS (2007) In vivo pons motion within the skull. J Biomech, 40: 92-99.

17. Kakaria UK, Chang SW, Theodore N, Sonntag VKH (2010) Atlas fractures. Neurosurgery, 66 (suppl.): A60-A67.

18. Krauss WE, Bledsoe JM, Clarke MJ, Nottmeier EW, Pichelmann MA (2010) Rheumatoid arthritis of the craniovertebral junction. Neurosurgery, 66 (suppl.): A83-A95.

19. Kuwazawa Y, Bashir W, Pope MH, Takahashi K, Smith FW (2006a) Biomechanical aspects of the cervical cord: effects of postural changes in healthy volunteers using positional magnetic resonance imaging. J Spinal Disord Tech, 19: 348-352.

20. Kuwazawa Y, Pope MH, Bashir W, Takahashi K, Smith FW (2006b) The length of the cervical cord: effects of postural changes in healthy volunteers using positional magnetic resonance imaging. Spine (Phila Pa 1976), 31: E579-E583.
21. Lao LF, Zhong GB, Li QY, Liu ZD (2014) Kinetic magnetic resonance imaging analysis of spinal degeneration: a systematic review. Orthop Surg, 6: 294-299.

22. Lord EL, Alobaidan R, Takahashi S, Cohen JR, Wang CJ, Wang BJ, Wang JC (2014) Kinetic magnetic resonance imaging of he cervical spine: a review of the literature. Global Spine J, 4: 121-128.

23. Magu S, Singh D, Yadav RK, Bala M (2015) Evaluation of traumatic spine by magnetic resonance imaging and correlation with neurological recovery. Asian Spine J, 9: 748-756.

24. Martin MD, Bruner HJ, Maiman DJ (2010) Anatomic and biomechanical considerations of the craniovertebral junction. Neurosurgery, 66 (suppl.): A2-A6.

25. Mesfar W, Moglo K (2013) Effect of the transverse ligament rupture on the biomechanics of the cervical spine under a compressive loading. Clin Biomech (Bristol, Avon), 28: 846-852.

26. Miura J, Doita M, Miyata K, Marui T, Nishida K, Fujii M, Kurosaka M (2009) Dynamic evaluation of the spinal cord in patients with cervical spondylotic myelopathy using a kinematic magnetic resonance imaging technique. J Spinal Disord Tech, 22: 8-13.

27. Morishita Y, Falakassa J, Naito M, Hymanshon HJ, Taghavi C, Wang JC (2009) The kinematic relationships of the upper cervical spine. Spine (Phila Pa 1976), 34: 2642-2645.

28. Morishita $Y$, Hymanson $H$, Miyazaki M, Zhang HH, He W, Wu G, Kong MH, Wang JC (2008) Review article: Kinematic evaluation of the spine: a kinetic magnetic resonance imaging study. J Orthopaed Surg, 16: 348-350.

29. Moulding HD, Bilsky MH (2010) Metastases to the craniovertebral junction. Neurosurgery, 66 (suppl.): A113-A118.

30. Pryputniewicz DM, Hadley MN (2010) Axis fractures. Neurosurgery, 66(suppl): A68-A82.

31. Sayit $E$, Daubs MD, Aghdasi B, Montgomery SR, Inoue $H$, Wang CJ, Wang BJ, Phan KH, Scott TP (2013) Dynamic changes of the ligamentum flavum in the cervical spine assessed with kinetic magnetic resonance imaging. Global Spine J, 3: 69-74.

32. Schlamann M, Reischke L, Klassen D, Maderwald S, Böhner V, Kollia K, Ladd ME, Forsting M, Wanke I (2007) Dynamic magnetic resonance imaging of the cervical spine using the NeuroSwing system. Spine (Phila Pa 1976), 32: 2398-2401.

33. Sen C, Shrivastava R, Anwar S, Triana A (2010) Lateral transcondylar approach for tumors at the anterior aspect of the craniovertebral junction. Neurosurgery, 66 (suppl.): A104-A112.

34. Singh H, Harrop J, Schiffmacher P, Rosen M, Evans J (2010) Ventral surgical approaches to craniovertebral junction chordomas. Neurosurgery, 66 (suppl.): A96-A103.

35. Smith JS, Shaffrey Cl, Abel MF, Menezes AH (2010) Basilar invagination. Neurosurgery, 66 (suppl.): A39-A47.

36. Steinmetz MP, Mroz TE, Benzel EC (2010) Craniovertebral junction: biomechanical considerations. Neurosurgery, 66 (suppl.): A7-A12.

37. Weintraub MI, Khoury A (1995) Critical neck position as an independent risk factor for posterior circulation stroke. A magnetic resonance angiographic analysis. J Neuroimaging, 5: 16-22.

38. Xiong C, Suzuki A, Daubs MD, Scott T, Phan K, Wang J (2015) The evaluation of cervical spine mobility without significant spondylosis by kMRI. Eur Spine J, 24: 2799-2806.

39. Yuan G, Dougherty L, Margulies SS (1998) In vivo human cervical spinal cord deformation and displacement in flexion. Spine (Phila Pa 1976), 23: 1677-1683. 